\title{
Analysis of Air Flow, Air and Fuel Induction for Internal Combustion Engine
}

\author{
Mohd Fitri Arshad ${ }^{1}$, Muhammad Faris Ahmad ${ }^{1}$, Amir Khalid ${ }^{1 *}$, Izuan Amin \\ Ishak $^{1}$, Shaiful Fadzil Zainal Abidin ${ }^{1}$, Mohd Azahari Razali ${ }^{2}$
}

${ }^{1}$ Centre of Automotive and Powertrain Technology, Faculty of Engineering Technology,

Universiti Tun Hussein Onn Malaysia, 84600 Pagoh, Johor, MALAYSIA

${ }^{2}$ Centre for Energy and Industrial Environment Studies (CEIES),

Faculty of Mechanical and Manufacturing Engineering,

Universiti Tun Hussein Onn Malaysia, Parit Raja, Batu Pahat, 86400 Johor, MALAYSIA

*Corresponding Author

DOI: https://doi.org/10.30880/japtt.2021.01.01.001

Received 24 August 2021; Accepted 11 October 2021; Available online 16 Disember 2021

\begin{abstract}
In an internal combustion engine, performance, efficiency and emission formation depends on the formation of air-fuel mixture inside the engine cylinder. The fluid flow dynamics plays an important role for airfuel mixture preparation to obtain the better engine combustion, performance and efficiency. This review article discuss the rotating flow (swirl and tumble) in premixed spark-ignition engine and its effect on turbulence generation and flame propagation. Rotating flow can substantially increase turbulence intensity for the duration of the combustion period. This review paper discusses the in-cylinder swirl and tumble flow that affects air induction during the combustion process in internal combustion engine. Alternatively, this study using computer simulation (Computational Fluid Dynamic, CFD) which offer the opportunity to carry out repetitive parameter studies. An integration-type flowmeter (IFM) also has been used which consists of ultrasonic flowmeter, that integrates the flowrate during the intake process, gives accurate measurements regardless of sampling time and frequency. Research parameter in this study was swirl and tumble that represents the fluid flow behavior occurred inside combustion chamber. Fuel injection and air mass also were the important parameters that have been discussed about in air induction process. The results obtain from the numerical analysis can be employed to examine the homogeneity of air-fuel mixture structure for better combustion process and engine performance.
\end{abstract}

Keywords: Swirl motion, tumble motion, air -fuel ratio

\section{Introduction}

Engine performance has been a serious problem that happened towards the car users for the last decades. By some estimation, many cars have difficulties on getting the efficient combustion during the combustion process. Thus, improper combustion led to the much emission of Hydrocarbon (HC) and Carbon Monoxide (CO) [1-5]. Others, have proposed in order to combat this issue, a research on air motion and air induction has been made to increase the combustion efficiency to get the proper air-fuel mixing during the intake. In addition, the objective of this research is actually to investigate the in-cylinder swirl and tumble flow that affect the induction during the combustion process in internal combustion engine. Next, the other objective was to identify the right amount of air fuel ratio during combustion for producing emission efficient vehicles. The scope of this research was the fluid motion within combustion chamber and air and fuel induction in internal combustion engine [6-12]. Research parameter in this study was swirl and tumble that represents the fluid flow behavior occurred inside combustion chamber. Fuel injection and air mass also were the important parameters that have been discussed about in air induction process. The focus was on air mass in throttle valve and fuel injection in combustion chamber. Alternatively, the research methodology of this 
study is using computer simulation (Computational Fluid Dynamic, CFD) which offer the opportunity to carry out repetitive parameter studies. An integration-type flowmeter (IFM) also has been used which consists of ultrasonic flowmeter, that integrates the flowrate during the intake process, gives accurate measurements regardless of sampling time and frequency [13-15].

\section{Experimental Setup}

\subsection{Computational Fluid Dynamics (CFD)}

Computer simulations (Computational Fluid Dynamics, CFD) offer the opportunity to carry out repetitive parameter studies with clearly defined boundary conditions in order to investigate various configurations. We investigate two important, common fluid flow patterns from computational fluid dynamics (CFD) simulations, namely, swirl and tumble motion typical of automotive engines. These two parameters represent the fluid flow behaviors occurred inside combustion chamber which influences the air streams to the cylinder during intake stroke and enhances greatly the mixing of air and fuel to give better mixing during compression stoke. In this study we are concerned on the swirl motion of inducted air during the suction stroke and during compression stroke. The results obtain from the numerical analysis can be employed to examine the homogeneity of air-fuel mixture structure for better combustion process and engine performance [16].

\subsection{Measurement of Air Mass Through A Throttle Valve}

Reciprocating piston motion caused the pulsating and reversal flow and make the measurement of flowrate in the intake pipe inaccurate. To reduce this measurement error, an accurate flowmeter and sampling method are necessary in order to give the best results. An integration-type flowmeter (IFM) which consists of ultrasonic flowmeter, which integrates the flowrate during the intake process, gives accurate measurements regardless of sampling time and frequency [17].

The IFM is able respond with quickly to measure the pulsating flow. Besides, it can measure the flow direction although the engine operating creates a flow reversal in intake manifold. In this study, to measure the air mass flowrate through a throttle valve, an operational amplier based integration circuit was constructed. Fig. 1 shows a schematic diagram of the IFM system. A flow signal created by an ultrasonic flowmeter is sent to a hardware integrator. A trigger signal created by an ECU, once every stroke, resets the integrator immediately after the ECU examines the integrated signal.

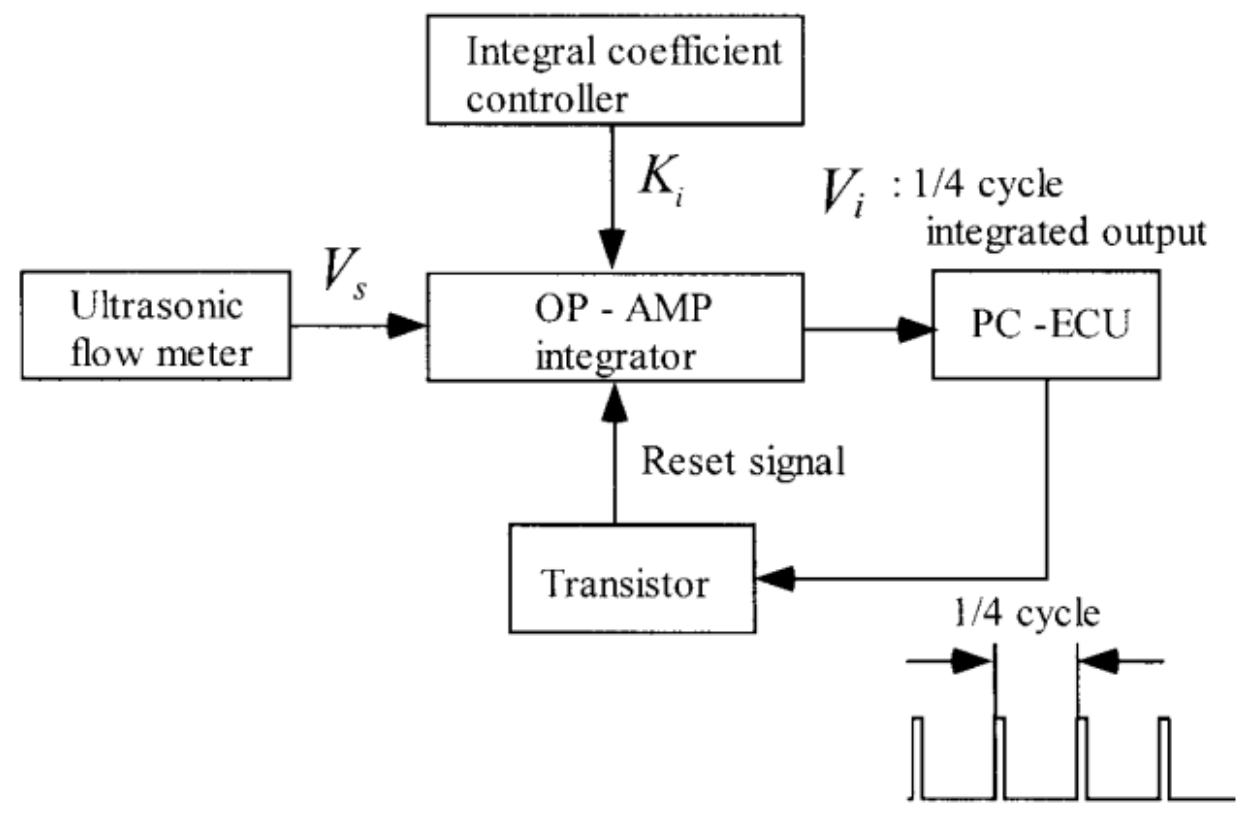

Fig. 1 - Schematic diagram of an IFM [17]

\subsection{Measurement of Injected Fuel Varied with Injection Pressure}

The injection pressure, which is the difference between the fuel rail pressure and the intake port pressure, varies with the engine operating conditions. Therefore, the amount of injected fuel fluctuates according to the injection pressure [18]. The dynamic quantity of injected fuel changes irregularly at the beginning of injection because of the injection dead time and is mainly affected by the injection pressure and battery voltage. The injection dead time 
increases at high injection pressures and low driving voltages. In this study, it is assumed are described as that the dynamic quantity of injected fuel is proportional to the injection duration. The cross-sectional view of an injector is shown in Fig. 2.

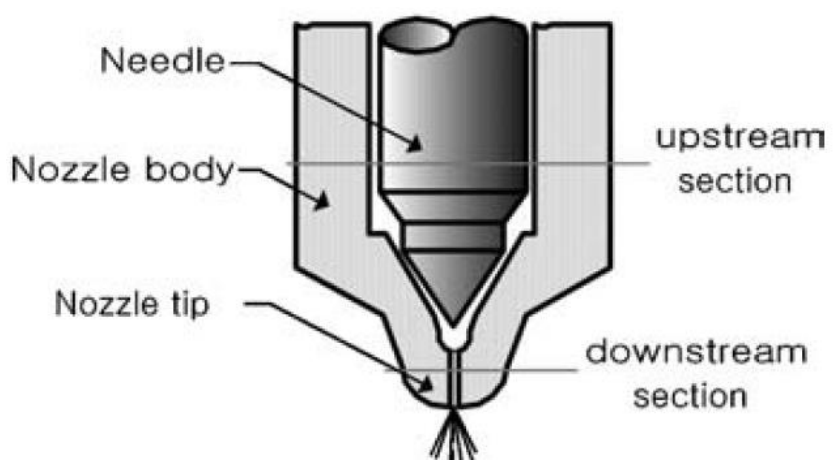

Fig. 2 - A cross-sectional view of an injector [18]

\subsection{Air Mass in Throttle Valve Together with The Injected Fuel Mass}

Fig. 3 shows an experimental set-up for a multipoint injection (MPI) engine equipped with an IFM. The throttle valve is controlled by a stepping motor to create transient conditions. Engine speeds are kept constant by an EC-type dynamometer connected directly to the crankshaft of the engine [19]. A sensor is placed at the junction of the manifold and the engine is controlled with an IBM PC-based PC-ECU controls.

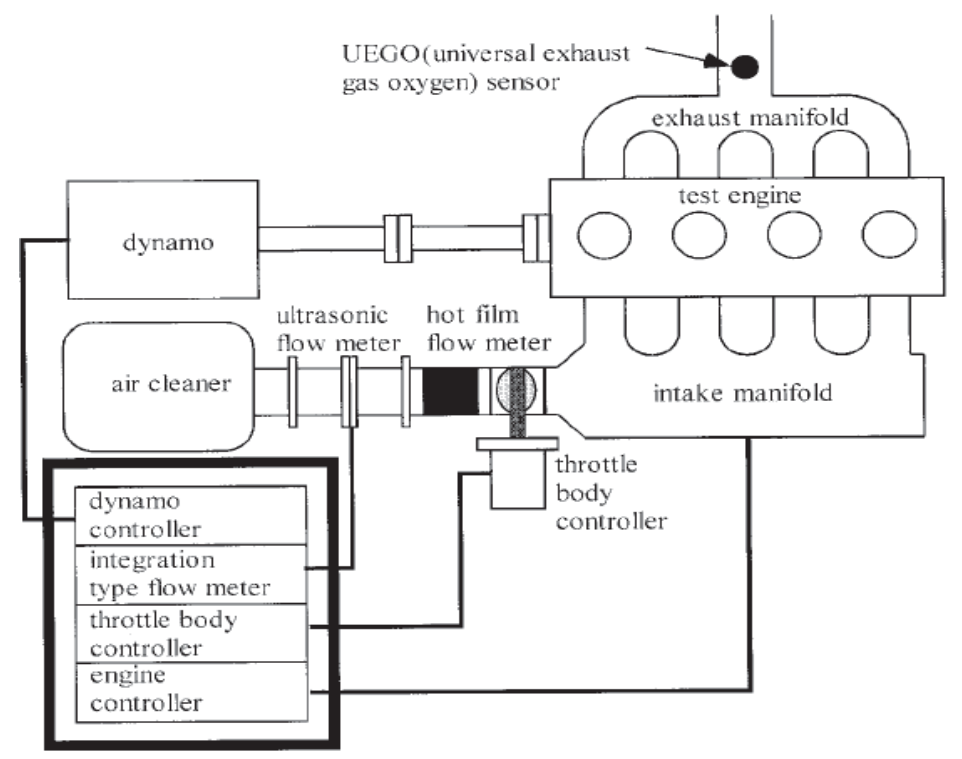

Fig. 3 - Experimental setup for AFR control [19]

\section{Result and Discussion}

\subsection{A Preliminary Study on Air Motion}

A premier combustion process within an engine block is relevant to the overall performance of many motorized vehicles. The in-cylinder charge motion often plays a dominant role in processes of preparation and conveyance of fuel mixture in the engine. The production of high turbulence intensity is one of the maximum critical factors for stabilizing the ignition technique and rapid propagation of flame, particularly inside the case of lean-burn combustion. In the flow within a cylinder, we can distinguish between two types of motion: swirl flow commonly found in diesel engines and tumble flow commonly found in gas engines. In both cases, rotational motion occurs about an axis, though the position of the respective axis is different as shown in Fig. 4. Air motion in the combustion chamber is three-dimensional [20]. 


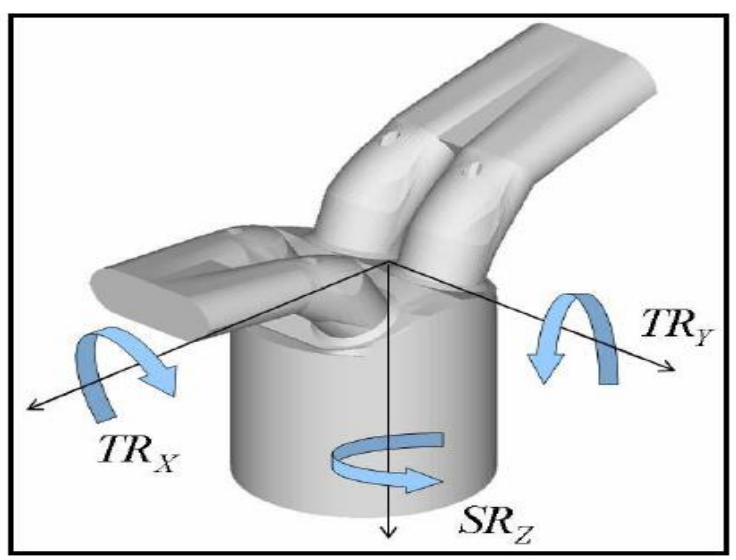

Fig. 4 - Definition of in-cylinder: sideways tumble TRx, normal tumble TRy and swirl SRz [20]

On a broader angle, it the in-cylinder movement can be characterized as a mixture of swirl, sideways-tumble and ordinary-tumble. They contribute to the improvement of engine performance with the aid of accelerating blending of fuel and induced air. As a result, it's miles necessary for development of an IC Engine with high compression ratio to recognize high turbulence depth and lean burn combustion. Swirl and tumble flows are constantly generated during intake and compression stroke of the inner combustion engine because of the high turbulence inside the cylinder [2021].

\subsubsection{Fluid Motion within Combustion Chamber: Swirl Motion}

Swirl is described as the massive scale vortex inside the in-cylinder fluid with the axis of rotation parallel to the piston axis. Swirl, taken into consideration as a -dimensional solid body rotation, persists via the compression and combustion methods. The decay of swirl in an engine cylinder in the course of the compression manner is noticeably small so that the overall angular momentum of the swirl vortex is sort of conserved. As an example, Liou and Santavicca (1983) located that turbulence become nearly homogenous and isotepric near TDC of their engine experiments. They also confirmed that turbulence depth near TDC at a given pace become $25-50 \%$ extra with swirl than without and then declined constantly with crank angle [21].

\subsubsection{Fluid Motion within Combustion Chamber: Tumble Motion}

Another intake-generated large-scale vertical flow pattern is the tumbling motion. The rotation axis of vortex is normal to the cylinder axis, resembling the rotation of a barrel. It is formed about a circumferential axis near the edge of the clearance volume in the piston crown or in the cylinder head, which is caused by squishing of the in-cylinder volume as piston reaches near TDC. Thus, tumbling motion is also called as vertical swirl or barrel swirl. To generate a pure tumbling motion for single intake-valve cylinders, the directional vector of intake jet should be on the plane defined by the cylinder axis and the intake valve axis. A tumbling flow with both the radial and the axial motion is therefore expected in the cylindrical coordinate. If an intake jet has only the tangential and the axial components in the cylindrical coordinate, a pure swirl flow is produced [21].

\subsubsection{A Test Run has been Performed}

The in-cylinder air motion before fuel injection process is very important to certify a proper air-fuel mixture. This is due to the fact that in-cylinder air motion plays a vital role on the complete combustion in the engine cylinder. A test run has been performed to obtain some details of in-cylinder air motion, at the motoring condition, for the suction and compression stroke of an engine. This was done to verify the velocity magnitude in the form of swirl and tumble flow. From Fig. 5, it can be seen that there are strong annular jet flows in the combustion chamber near the valve curtains. It because the flow and velocity field in this degree of crank angle reaches to the maximum value where the intake valves almost open at the maximum lift distance [22-23]. 

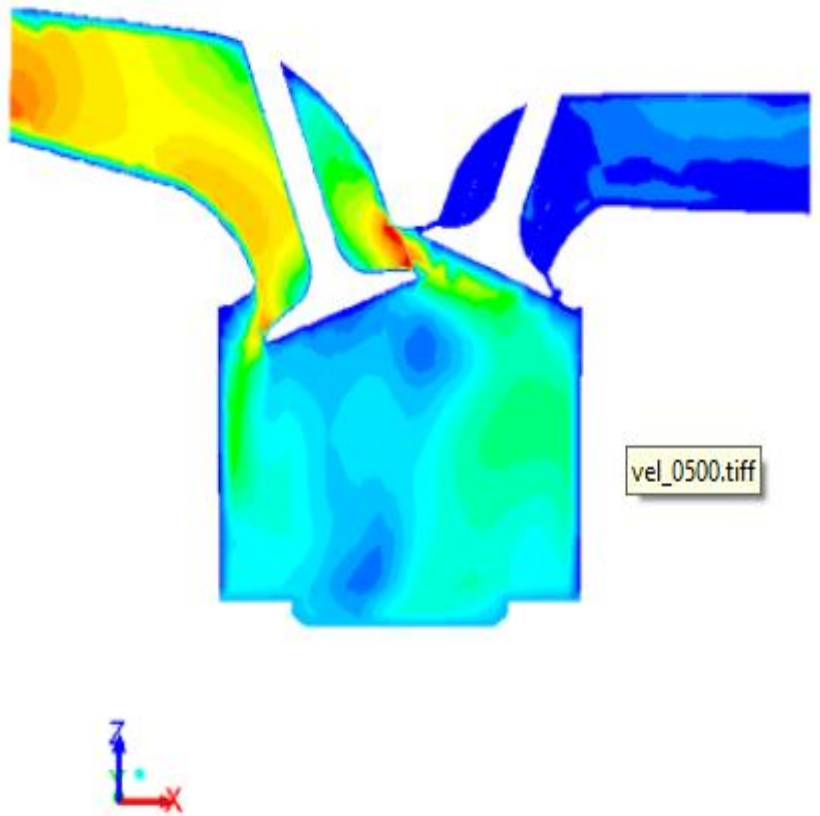

Fig. 5 - CFD simulation of air flow in the IC Engine [24]

This strong annular jet flows make a clockwise or counter-clockwise swirl on the intake valve. The piston speed is kept constant at $2500 \mathrm{rpm}$. A clockwise vortex is visible to be formed at the centre of the engine cylinder, under intake valves. This is a due to the jet motion of air which does not strike the cylinder walls but directly flows to the centre of the cylinder. The jet of air which strikes the walls of the cylinder creates an elongated vortex along the wall [24].

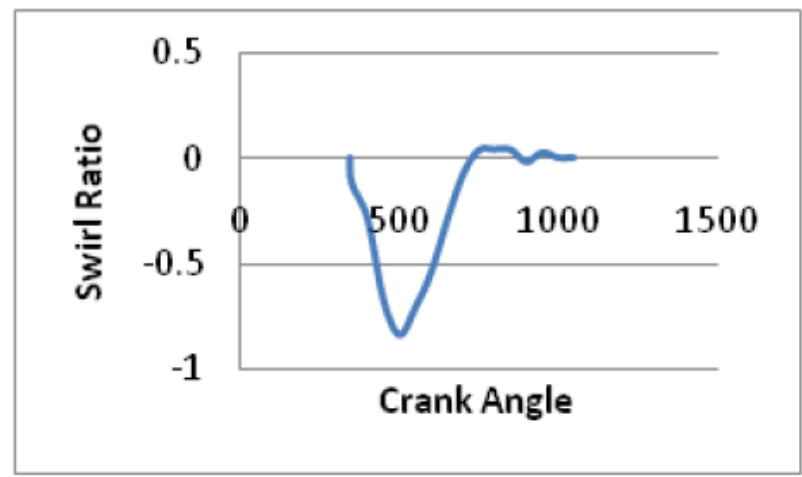

Fig. 6 - SR vs Crank Angle-curve [18]

The swirl ratio is observed to begin with a negative tendency. Maximum swirl ratio is achieved around $500^{\circ}$, which is about $160^{\circ}$ crank angle after TDC, as the piston reaches the maximum instantaneous speed and the valve opening is at its maximum distance as seen in Fig. 6. Beyond this point the swirl ratio gradually decreases towards the end of the suction stroke. The trend continues into the compression stroke as well due to the friction at the cylinder wall. During the compression stroke, swirl flow interacts with the tumble flow forming squish air flow motion. The nature and 
variation of the in-cylinder tumble flow (normal) can be seen in Fig. 7. Tumble about the y-axis becomes negative at the beginning of the suction stroke and falls to minimum at around $10^{\circ}$ after TDC. It can be then observed that there is rapid change in the curve and the ratio begins to increase [24].

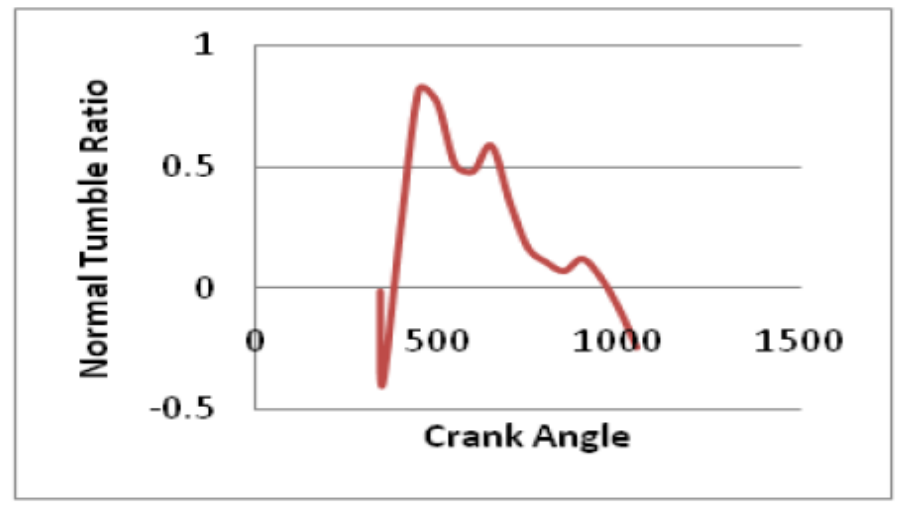

Fig. 7 - Try vs Crank Angle-curve [24]

A maximum tumble is achieved at about $120^{\circ}$ after TDC. It may be due to the jet air flow during the valve opening that the normal tumble decreases in the beginning and increases into the early part of the compression stroke. Thereafter, the normal tumble ratio would decrease, with a small increase in between, during the further crank angles.

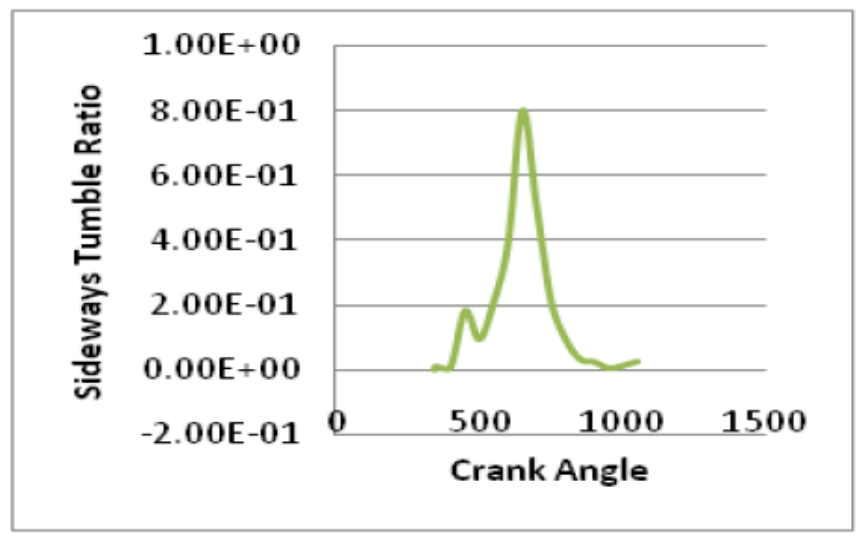

Fig. 8 - Try vs Crank Angle-curve [24]

The tumble ratio in the sideways direction can be seen in Figure 8. The graph shows the sideways tumble ratio and its variation inside engine cylinder. Tumble affect about the $\mathrm{x}$-axis is very low in the beginning of the suction stroke. It then increases gradually and reaches a peak value in the compression stroke. A dominant tumbling motion has been developed at this.

\subsection{A Preliminary Study on Air and Fuel Induction}

\subsubsection{Air Mass in Throttle Valve Together with The Injected Fuel Mass}

The air mass at the throttle valve overshoots during tip-in where the intake manifolds pressure increase. This pressure change in turn increases the in-cylinder air mass. The in-cylinder fuel mass is controlled so that the in-cylinder air fuel ratio (AFR) is kept at the desired value. As the injected fuel mass increases, the fuel mass in the puddle also increases. This modification in fuel mass in the puddle is provided via the injected fuel overshoot shown in Fig. 9 which increases similarly while the engine coolant temperature is low [25-27].

The air mass measured at the throttle valve together with the injected fuel mass during tip-in are shown in Fig. 9, as well as the fuel puddle mass and the fuel mass inducted into the cylinder. 


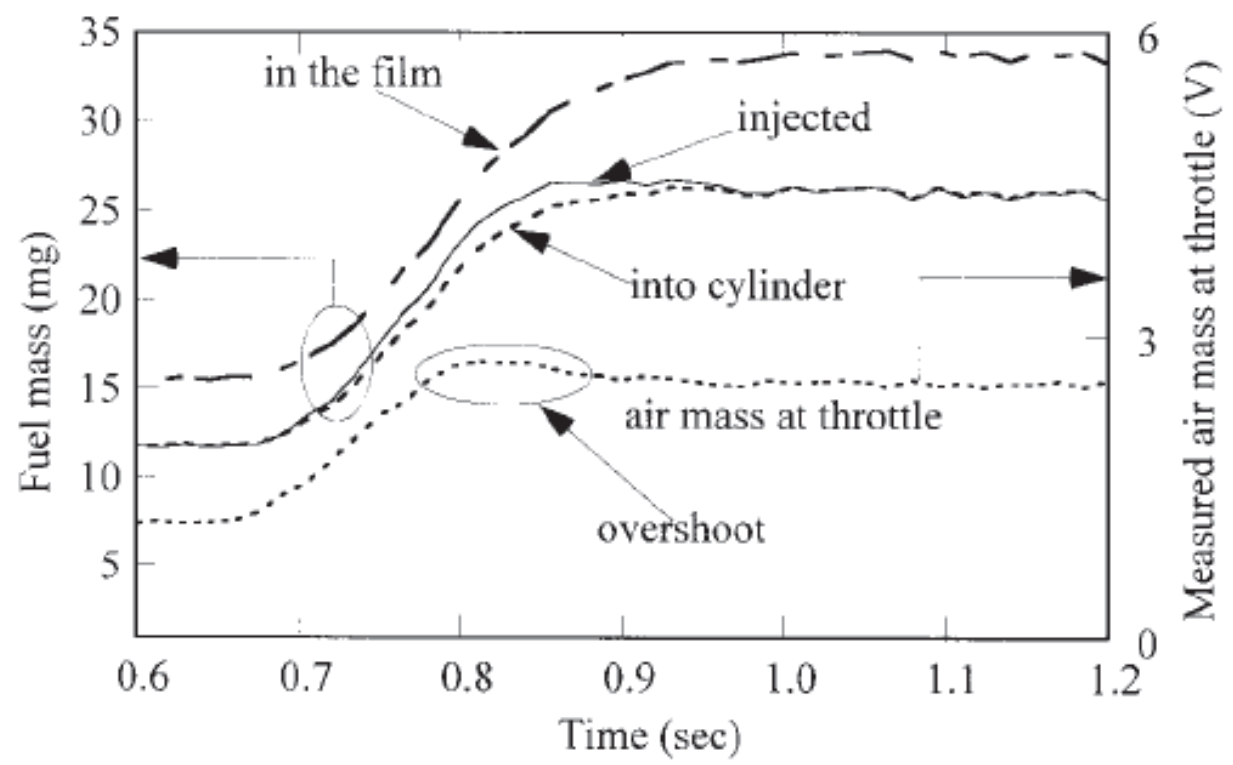

Fig. 9 - Measured air mass at the throttle valve and fuel mass into cylinders, injected and in the fuel film during tip-in [25]

\section{Conclusion}

Air motions in the Internal Combustion Engines are motion in the form of rotating flow that occurred repeatedly during the combustion. In this study, two type of motions is been recognized which are swirl and tumble. Creating a swirling vortex in the cylinder has been identified as a way of improving turbulence stages during the compression stroke since the old Internal Combustion engines. Swirl build up turbulence during the compression stroke through following methods: Turbulence developed by the shear at the wall is transfer throughout the bulk of the flow by diffusion and generated secondary flow or any protruding objects not on the axis of rotation of the swirl vortex will create turbulence through shear and vortex shedding. The fundamental of tumble occurs during the intake stroke. This vortex is compressed during compression stroke and its increase its rate of rotation to conserve angular momentum. The increasing of the compression, the vortex turned into more non-circular patterns. The vortex reaches a critical point beyond with the vortex breaks down into smaller vortices. These vortices decay into smaller turbulent structures, thereby enhancing the turbulent stages.

Air and fuel induction starts from the intake system which consist of an intake manifold, throttle, intake valves, and either their fuel injectors or a carburetor to add fuel. The mass of air flow and the injected fuel mass must enter the chamber in correct amount. Therefore, the AFR is important in order to have an efficient engine of vehicles. The method of using the IFM with ultrasonic flowmeter proved to be efficient to control the AFR. Besides, the in-cylinder air mass of the current time step can be calculated accurately using an IFM and manifold pressure sensor. Lastly, air masses in throttle valve together with the injected fuel mass are successfully be measured.

\section{Acknowledgement}

The authors would like to thank the Ministry of Education Malaysia for supporting this research under Fundamental Research Grant Scheme (FRGS) Vot K218, K 224 and also Research Fund Universiti Tun Hussein Onn Malaysia (H802) and GPPS vot. U749).

\section{References}

[1] V. V. Prathibha Bharathi, Dr. G. Prasanthi (2013). The Influence of Air Swirl on Combustion and Emissions in a Diesel Engine. International Journal of Solids and Structures. Volume 3, Issues 2, May Oct2013, pg 86-97

[2] Z. Barbouchi* and J. Bessrour (209). Turbulence study in the internal combustion engine. Journal of Engineering and Technology Research Vol.1 (9), pp. 194-202, December, 2009

[3] Priscilla, Meena. P (2013) A Comprehensive Study on In-Cylinder Ic Engine Due to Swirl Flow. International Journal of Engineering Research \& Technology (IJERT). ISSN: 2278-0181. Vol. 2 Issue 7, July - 2013

[4] J. Kim, T. Kang, S. K. Kauh. (2001) Transient air-fuel ratio control of a multi-point injection engine with an integration-type ultrasonic flowmeter. Journal of Automobile Engineering, 215(3), $385-391$. https://doi.org/10.1243/0954407011525719 
[5] H. Sim, K. Lee, N. Chung, M. Sunwoo. (2005). A study on the injection characteristics of a liquid-phase liquefied petroleum gas injector for air-fuel ratio control. Journal of Automobile Engineering, 219(8), 1037-1046. https://doi.org/10.1243/095440705X34621

[6] Baharol Maji, D. S., \& Mustaffa, N. (2021). CFD Analysis of Rear-Spoilers Effectiveness on Sedan Vehicle in Compliance with Malaysia National Speed Limit. Fuel, Mixture Formation and Combustion Process, 3(1)

[7] Khalid, A., Ja'at, N., Mohd Johari, A., \& Maheswaran, K. (2019). Investigation on the Flame Propagation of Ethanol - Gasoline Blend in Different Ambient Pressure in a Constant Volume Chamber. Fuel, Mixture Formation and Combustion Process, 1(1)

[8] Azlan, A. N., Abd Rashid, R., Ishak, I. A., Mohd Salleh, Z., Madon, R. H., Ishak, M. Z., \& Samiran, N. A. (2021). Three Dimensional CFD Simulation of Air-Blown Gasification in a Downdraft Reactor: Effect of Throat Diameter and Air Inlet Position. Fuel, Mixture Formation and Combustion Process, 3(1)

[9] Radzali, M. H., Hakim Zulkifli, A. F., Khalid, A., Radzali, M. H., \& Jacob, D. W. (2020). Effect of MethanolGasoline Blend and Ambient Pressure on Flame Propagation and Exhaust Emission of Spark Ignition (SI) Engine. Fuel, Mixture Formation and Combustion Process, 2(2)

[10] Salleh, H., Khalid, A., Hashim, M. A., Razzaly, W., Amirnordin, S. H., \& Suardi, M. (2020). Effects of Mass Flow Rate on Combustion Characteristics and Emissions of Micro Gas Turbine. Fuel, Mixture Formation and Combustion Process, 2(1)

[11] Jie, Y. G., Khalid, A., Abd Rahman, A. A., Sulaiman, S., Mohamed, N., Zulkifli, A. F. H., Leman, A. M., \& Jacob, D. W. (2021). Biodiesel Pilot Plant System and Conversion Technology of Multiple Feedstocks. Fuel, Mixture Formation and Combustion Process, 3(1)

[12] Azizul, M. A., Abdullah, M. I., Khalid, A., Mustaffa, N., Ishak, I. A., Manshoor, B., Didane, D. H., \& Andsaler, A. R. (2021). Effects of Ethanol-gasoline and Methanol-gasoline on Spray Evaporation and Flame Propagation. Fuel, Mixture Formation and Combustion Process, 3(1)

[13] Davis, G, C. Mikulec, A., Kent, J.C. (1986). Modelling the effect of swirl on turbulence intensity and burn rate in S.I engines and comparison with experiment, SAE Paper 860325

[14] Nish Iwaki, K., Prediction of three-dimensional fluid motion during intake process and swirl ratios in four cycle engines. Intake Symposium on Diagnostics and Modelling of Combustion in Reciprocating Engines, Tokyo, September (1985)

[15] Benny Paul1, V. Ganesan, Flow field development in a direct injection diesel engine with different manifolds, International Journal of Engineering, Science and Technology Vol. 2, No. 1, 2010

[16] A study on combines effects between swirl and tumble flow of intake port system in cylinder head. Jeong Eue Yun, Jae-Joon Lee, Engine test team, Tech center, Daewoo Motors Co., 199 Chongchondong Pupyong-gu, Inchon, 401-714, South Korea.C., MIKUL

[17] C. Garth, R. S. Laramee, X. Tricoche, J. Schneider, and H. Hagen. Extraction and visualization of swirl and tumble motion from engine simulation data- available at http://www.vrvis.at/scivis/laramee/MotionExtracted/.J

[18] Huang Rf, Huang CW, Yang HS, Lin TW, Hsu WY (2005). Topological flow evolutions in cylinder of motored engine during intake and compression strokes. J. Fluids Struct. 20: 105-127

[19] Shivaprasad K. V, Dr. Kumar G. N, Dr. Gurusprasad K.R. Performance, Emissoon and Fuel Induction System of Hydrogen Fuel Operated Spark Ignition Engine. International Journal of Modern Engineering Research (IJMER), Vol.2, Issue .1, Jan-Feb 2012.pp-565-571

[20] Durgeshchandrasinh I. Rathod Chirag D Singal. A Provision of Air Induction Valve in 4-Stroke Petrol Engine to Reduce the Exhaust Emission. International Journal of Advance Engineering and Research Development. Volume 2, Issue 2, February -2015

[21] Dipak C. Talele, Dr. Dheeraj S. Deshmukh, Dr. Prashant P. Bornare. Effect of Air Induction System Design on Compression Ignition Engine Performance. International Journal of Science, Spirituality, Business and Technology (Ijssbt). Vol. 4, No. 2, May 2016 ISSN (Print) 2277-7261

[22] Ajay Kumar Singh. Dr. Atul Lanjewar Dr. A. Rehman. Current Status of Direct Fuel Injection in Two Stroke Petrol Engine. Journal of Mechanical and Civil Engineering (IOSR-JMCE). Volume 12, Issue 2 Ver. II (Mar Apr. 2015), pg 86-93

[23] J. B. Heywood; -Internal Combustion Engine Fundamentals; McGraw-Hill, ISBN 0-07-100499-8, (1988) pp. 635-643

[24] H. Rui, L. Honggang, Y. Ronghai et al., "Influence of water induction on NOx emission of diesel engine through air intake," Journal of Dalian Jiaotong University, vol. 34, no. 4, pp. 32-34, 2013

[25] P. Ragupathi, S. Rajkumar, R. Sameer Hussain, Design and Analysis of Diesel Engine Intake Manifold Using CFD Simulation, International Journal of Modern Trends in Engineering and Science, Volume 1, Issue 1, May 2014, ISSN: 2348-3121 pp.174-179

[26] M. Schechter and M.B. Levin. "Air-forced fuel injection system for 2 strokes D.I. gasoline" SAE Technical Paper, 1991 [1991-02-10. Paper 910664]

[27] Norihiko Nakamura, Toyokazu Baika and Yoshiaki Shibata, (1986), "Multipoint spark ignition for lean combustion", SAE paper no. 852092 